\title{
Research on the Relationship between Young University Teachers' Occupational Stress and Performance
}

\author{
Yuan-YuanLAN ${ }^{1, a,{ }^{*}}$, Xiao-TingQU ${ }^{1 . b}$, Huan LIU ${ }^{1, c}$, Ying QIN $^{1, d}$, \\ ${ }^{1}$ Beijing Jiaotong University, Beijing, China

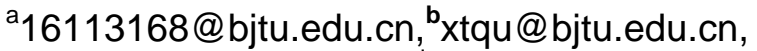 \\ c16120700@bjtu.edu.cn, dqinying@bjtu.edu.cn
} Keywords: Young university teachers, Self-efficacy, Occupational stress, Occupational
performance.

\begin{abstract}
As the most dynamic group of university teachers, the performance of young teachers greatly affects the overall quality of college faculty. In this study, we selected 272 young university teachers as research samples, and we used questionnaires and semi-structured interviews to collect data.To make the findings more validate, we used SPSS20.0as the statistical analysis tool and applied hierarchical regression analysis to analyze the relationship among occupational stress, self-efficacy and occupational performance. The result suggests that university young teachers' occupational stress is positively related to occupational performance, and self-efficacy of university young teachers plays a moderating role between occupational stress and occupational performance. However, further interviews indicate that when young teachers feel over-stressed, their performance will reduce. The conclusion of our research is helpful for the supervisors of a university to formulate the teaching staff development planning, training management and other policies scientifically and reasonably.
\end{abstract}

\section{Introduction}

With the rapid development of society, individuals generally receive a higher level of education, and almost all aspects of the society require university teachers to have a high level of teaching ability, occupational performance and so forth. However, university teachers, especially young teachers, not only have to undertake a large number of teaching and research tasks but also face the pressures of life and development such as marriage, housing, children's education, personal development, job evaluation etc. There are several studies suggest that when occupational stress increases, the occupational performance will also improve. In the meantime, some research finds that occupational performance will decrease when occupational stress increases. So, what's the relationship between occupational stress and occupational performance in the context of university young teachers?

When exploring the relationship between occupational stress and occupational performance, the role of self-efficacy is increasingly valued by scholars. Self-efficacy is the individual's confidence in self-ability which reflected when completing tasks [1], and self-efficacy has a significant positive effect on the improvement of work performance [2]. Although there are numerous researches on self-efficacy, scant theoretical and empirical studies paid attention to the relationships among work stress, work performance and self-efficacy. In terms of university young teachers, the studies were less. In this study, we used university young teachers in Beijing as samples to explore the above problems so as to fill the gap in the existing literature. Specifically, this study mainly studies two questions: First, what is the relationship between university young teachers' work pressure and work performance? Second, what is the impact of self-efficacy on the relationship between job stress and job performance?

The contribution of this research is that this is the first empirical research on exploring the relationship among university young teachers' work stress, work performance and self-efficacy. The findings of this study help college administrators to understand the psychological differences among university young teachers more initiatively and adopt different measures to enhance the performance of university young teachers. 


\section{TheoryandHypotheses}

\section{Occupational Stress andOccupationalPerformance}

Previous studies haven't come to a consistent conclusion on the relationship between occupational stress and occupational performance. There are mainly four theories about the relationship, including moderation theory [3], inhibition theory [4], irrelevant theory and motivation theory [5]. Specific to university teachers, Jacobs and Tytherleigh et al. (2007)found that there is a negative correlation between job stress and job performance of university teachersthrough the study of 13 English university teachers [6]. By investigated he work pressure and work performance of college teachers, Tian-Yin Liu (2010) found that the multi-step and small-scale stress management measures have significantly improved the work performance [7]. Jian-Wei Li (2012) argued that there is a significant negative correlation between job stress and job performance in university teachers through the research on 450 university teachers [8]. According to a survey of 164 teachers in Zhejiang universities, Yang-Chun Fang (2013) found that job stress significantly affected job performance, when the workload was heavy, and long-term stressors were negatively correlated with relationship performance [9]. Based on the analysis above, we put forward an assumption as follow:

H1: There is a significant correlation between occupational stress and occupational performance among university young teachers.

\section{Moderating Effects of Self-efficacy}

With the deepening researches on self-efficacy, Bandura (1997) developed the concept of self-efficacy based on the social cognition theory and extended self-efficacy to the field of organization. He defined self-efficacy as confidence and belief in ability that people own to reach their own goals and fulfill certain tasks [10]. Yuan-Yong GuandJing-Sheng Peng (2011) proposed that self-efficacy is individual's belief that whether he or she can have creative performance in work or not [11]. When confronting the same difficulties, the more self-efficacy individuals have, the more likely they overcome the difficulties [12].

The research of Chang-Qin Lu et al. (2006) suggested that managers with higher self-efficacy have higher work performance [13]. Dong-Dong Feng et al. (2008) found that general self-efficacy has a significant regulatory effect on the relationship between insecurity and work performance [14]. Xiao-Bin Meng and Xiao-Dong Xu (2008) further argued that self-efficacy has a significant effect on the relationship between job stress and job performance [15]. Based on the findings of previous studies, weput forward the hypothesis as follow:

H2: Self-efficacy of university young teachers has a significant moderating effect on occupational stress and occupational performance.

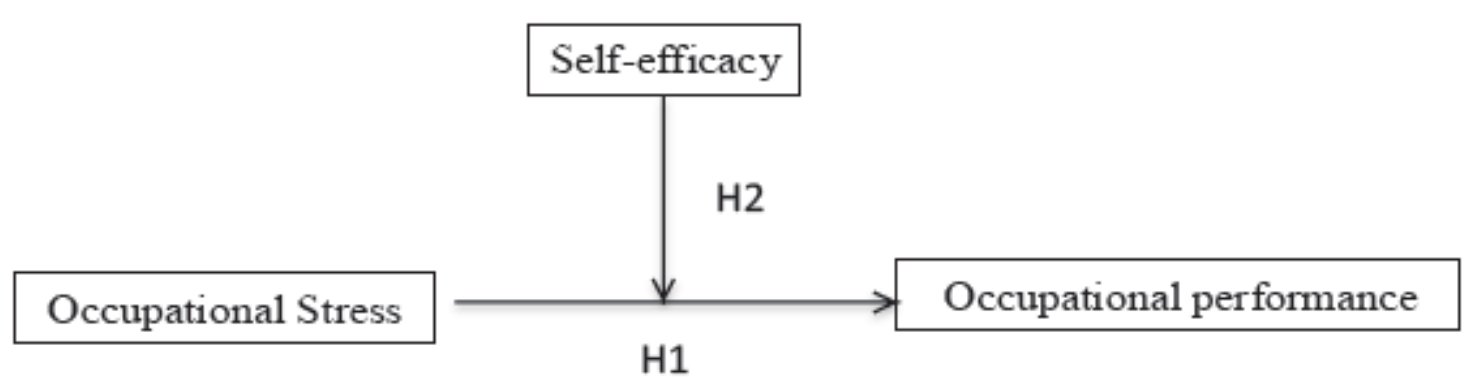

Figure 1Conceptual Model

\section{Methods}

\section{Sample and Procedure}

The data were collected through printed questionnaires and online questionnaires inseveral 
universities in Beijing, China.First of all, we interviewed same teachers in different universities and learned that some teachers complained that occupational stress was heavy for them and some teachers didn't think so. It means that collect samples from those universities were suitable. It should be noted that scholars do not hold a consensus on the definition of "youth". Therefore, it is necessary to define the concept of the young university teacher. World Health Organization defined the age of this group is 14-44 years old [16]. Some scholars define the age of young university teachers as no more than 35 years old [17] [18]. However, most individuals become university faculty when they are about 30 years old or even older than 30 years old in reality. What's more, the majority of college faculty who are qualified as professors are older than 40 years old. In addition, the age of young teachers applying for provincial and ministerial projects cannot above 35 years old, apply for national research projects of young teachers cannot above 40 years old. Hence, based on these factors, the university young teachers in our study are the first-line teachers who are engaged in teaching and research task andunder 40 (including 40) years old.

Before handing out questionnaires, we explained the importance of the answers' reality to scientific research and guaranteed the anonymity of the research participants.After confirming every participant understood how to complete questionnaires, we gave each participant a questionnaire. And in order to ensure the validity of online questionnaires, questionnaires were issued separately to participants. Excluding the incomplete or non-conforming questionnaires, 272 valid questionnaires were finally obtained. As shown in Table 1, 59.9\% were women, 40.1\% were male, $84.2 \%$ were $30-40$ years old, and $69.2 \%$ had $\mathrm{Ph}$. $\mathrm{D}$ degree.

Table 1Effective Questionnaire Statistics

\begin{tabular}{|l|l|l|}
\hline \multirow{2}{*}{ Demographic variables } & category & percentage (\%) \\
\hline \multirow{3}{*}{ Age } & Male & 40.1 \\
\cline { 2 - 3 } & Female & 59.9 \\
\hline \multirow{3}{*}{ Education } & 25-29 years old & 15.8 \\
\cline { 2 - 3 } & $30-34$ years old & 40.0 \\
\cline { 2 - 3 } & 35-40 years old & 44.2 \\
\hline & Bachelor & 0.8 \\
\cline { 2 - 3 } & Master & 30.0 \\
\cline { 2 - 3 } & Doctor & 69.2 \\
\hline
\end{tabular}

\section{Measures}

In order to minimize the culture difference between the east and the west, we applied the standard translation and back-translation process to interpret scales that was originally developed in English, and for some specific items, we made some change to make sure they were consistent with Chinese context. For all measures, we used a 5-point Likert Scale, from 1 strongly disagree to 5 strongly agree.

Occupational stress. Young teachers were asked to report occupational stress with a 20-item occupational stress scale (Alpha $=0.91$ ) developed by Archibong et al. (2010) [19], which included the following sample item: "Get along well with students."

self-efficacy.Youngteachers were asked to report self-efficacy with a 10-item self-efficacy scale (Alpha = 0. 94) developed by Riggs ML (1994) [20], which included the following sample item: "I believe I have the ability to do my work."

Occupational performance. Young teachers were asked to report occupational performance with a 21-item occupational performance scale (Alpha $=0.65)$ developed by De-Cheng Yu (1996), which included the following sample item: "I often collaborate with colleagues who belong to the same team.”

Control variables. To make sure our research more scientifically, we controlled gender, age and education of university young teachers. 


\section{Results}

\section{Validity test}

In order to test the reliability of those questionnaires, SPSS 20.0 was used to test the validity of occupational stress questionnaire, self-efficacy questionnaire and occupational performance questionnaire.

First of all, the test result ofoccupational stress scale's validity is shown in Table 2. It is clear that KMO value of occupational stress scale is 0.886 , greater than the standard of 0.70 , which means that its validity is good. Secondly, according to Table 2, the KMO value of self-efficacy scale is 0.846 , greater than the standard of 0.70 , too. Thirdly, Table 2 also shows that the KMO value of occupational performance scale is 0.936 , greater than the standard of 0.70 .

Table 2 KMO Test and Bartlett Test Results $(\mathrm{N}=272)$

\begin{tabular}{|l|l|l|l|l|}
\hline \multicolumn{2}{|l|}{} & $\begin{array}{l}\text { OccupationalStress } \\
\text { Scale }\end{array}$ & $\begin{array}{l}\text { self-efficacy } \\
\text { Scale }\end{array}$ & $\begin{array}{l}\text { OccupationalPerformance } \\
\text { Scale }\end{array}$ \\
\hline \multirow{2}{*}{ KMO Value } & 0.886 & 0.846 & 0.936 \\
\hline \multirow{2}{*}{$\begin{array}{l}\text { Bartlett's Test } \\
\text { of Sphericity }\end{array}$} & X2 & 2893.871 & 1444.888 & 3508.307 \\
\cline { 2 - 5 } & df & 190 & 45 & 210 \\
\cline { 2 - 5 } & 0.000 & 0.000 & 0.000 \\
\hline
\end{tabular}

\section{Correlation Analysis}

The correlation among variables is shown in Table 3. It is easy to know that there is a significant positive correlation between job stress and job performance. Specifically, interpersonal stress was positively correlated with task performance and relationship performance $(\mathrm{r}=0.446, \mathrm{p}<0.01 ; \mathrm{r}=$ 0.531, p <0.01); job development stress was positively correlated with task performance and relationship performance $(r=0.455, \mathrm{p}<0.01 ; \mathrm{r}=0.366, \mathrm{p}<0.01)$. The research stress was positively correlated with task performance and relationship performance $(r=0.519, p<0.01 ; r=0.428, p$ $<0.01)$. Task performance and relationship performance were positively correlated $(r=0.515, p$ $<0.01 ; \mathrm{r}=0.468, \mathrm{p}<0.01$ ). All of theseshows that in terms of statistics, the greater the interpersonal pressure of university young teachers, the higher the task performance and the relationship performance. The greater the stress of career development of university young teachers, the higher the task performance and the relationship performance.The greater the stress of scientific research of young teachers, the higher task performance and relationship performance; the greater the career development stress of university young teachers, the higher the task performance and relationship performance. Hypothesis $\mathrm{H} 1$ has been proved.

\section{Moderated Analysis}

In order to further verify the relationship among those variables, we analyzed the main variables by using the method of hierarchical regression after controlling the influence of gender, age and education. Before conducting this analysis, we normalized independent and regulatory variables and then examined whether there was multicollinearity between them. The results showed that VIF was less than 2, no significant co-linearity was found between these variables, which means that the results of regression analysis were reliable. Specific regression analysis results are shown in Table 4.

\section{Hierarchical Regression Analysis among Occupational Stress, Self-efficacy And TaskPerformance}

Firstly, taking the demographic variables such as gender, age and education and task performance to conduct the regression analysis and form model 1 . The results of model 1 show that the effect of these demographic variables on task performance is not significant. Secondly, in order to further 
verify the influence of occupational stress on task performance, we add four kinds ofoccupational stress to form Model 2. According to the results, model 2 is significant ( $R 2=0.385$, regression coefficients are $0.206 * *, 0.305^{* * *}, 0.313^{* * *}$, respectively) and it shows that interpersonal stress, research stress and teaching stress can exert an impact on task performance. The results can account for $38.5 \%$ of the variation in task performance, 37.6\% more than Model 1's explanation. Thirdly, add self-efficacy into model 2 to form model 3. According to the model results, we can see that Model 3 is significant, too ( $\mathrm{R} 2=0.389$, regression coefficient is $0.60 *$ ), and increases the explanatory power by $0.4 \%$ than Model 2 . Finally, based on the model 3, the interaction among the four dimensions of occupational stress and self-efficacy is added to form model 4. The model was established $(\mathrm{R} 2=0.409$, regression coefficient was $0.074 *, 0.168 *, 0.558 *, 0.588 *$ respectively), which increased by $2 \%$ than model 3 , indicating that self-efficacy plays a positive role in the relationship between occupational stress and task performance.

\section{Hierarchical Regression Analysis among Occupational Stress, Self-efficacy And RelationshipPerformance}

To begin with, taking the demographic variables such as gender, age and education and relationship performance to conduct the regression analysis and form model 5. The results of model 5 show that the effect of these demographic variables on relationship performance is not significant.Second, in order to further verify the influence of occupational stress on the relationship performance, we added the four dimensions of occupational stress to form the model 6 . According to the results of the model, model 6 holds ( $\mathrm{R} 2=0.355$, regression coefficients are $0.951 * *, 0.424 * * *, 0.538 * * *$, respectively) and it indicates that the effects of interpersonal stress, research stress and teaching stress on relationship performance are significant, and it can account for $35.5 \%$ of the variation in relationship performance with an increase of 35.0\% over Model 5. Third, we added self-efficacy to model 6 to form model 7 . According to the model results, we found that model 7 holds $(\mathrm{R} 2=0.356$, regression coefficient is $0.51 *$ ), and increased the explanatory power by $0.1 \%$ than model 6 . Finally, based on the model 7, we added the interaction terms of the four dimensions of occupational stress and self-efficacy respectively to form model 8 . The model was established ( $\mathrm{R} 2=0.386$, the regression coefficients were $0.403 *, 0.071 *, 1.312 *, 1.797 *$ respectively), which increased by $3 \%$ than the model 7 , indicating that self-efficacy positively moderated the relationship between occupational stress and occupational performance.

To further explore the regulatory role of self-efficacy, we conducted a slope analysis and the results were shown in Figure 2, Figure 3, Figure 4 and Figure 5.

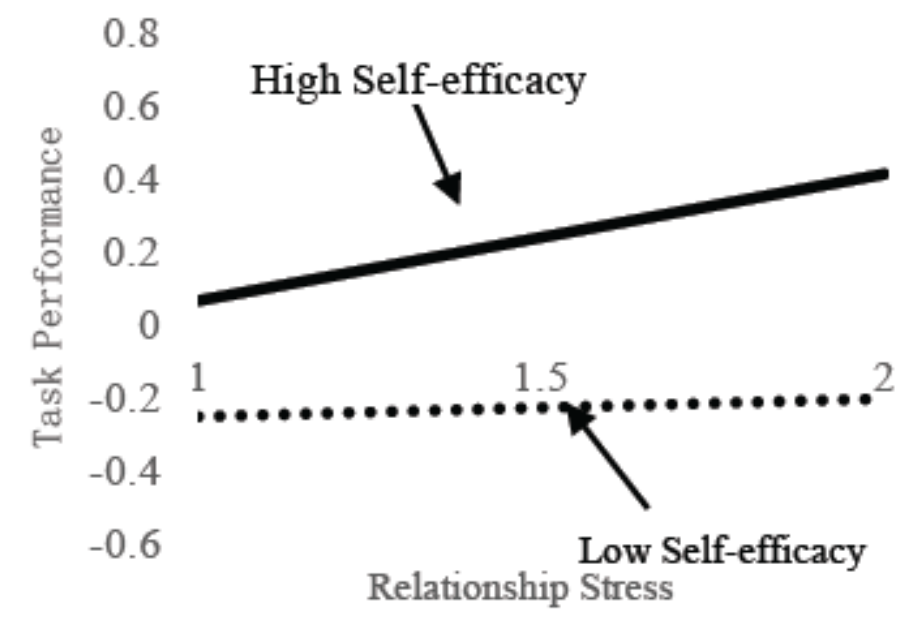

Figure 2 The First Moderating Effect of Self-efficacy 


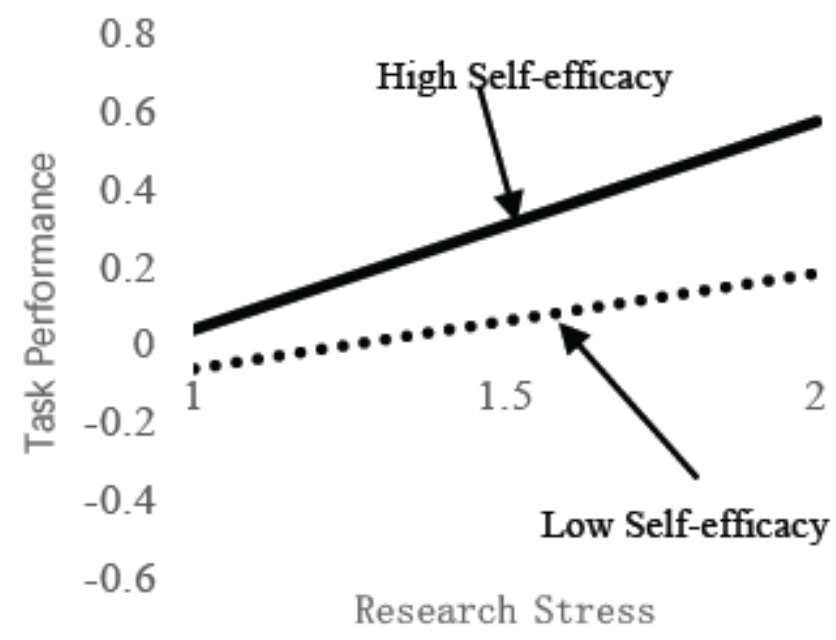

Figure 3 The Second Moderating Effect of Self-efficacy

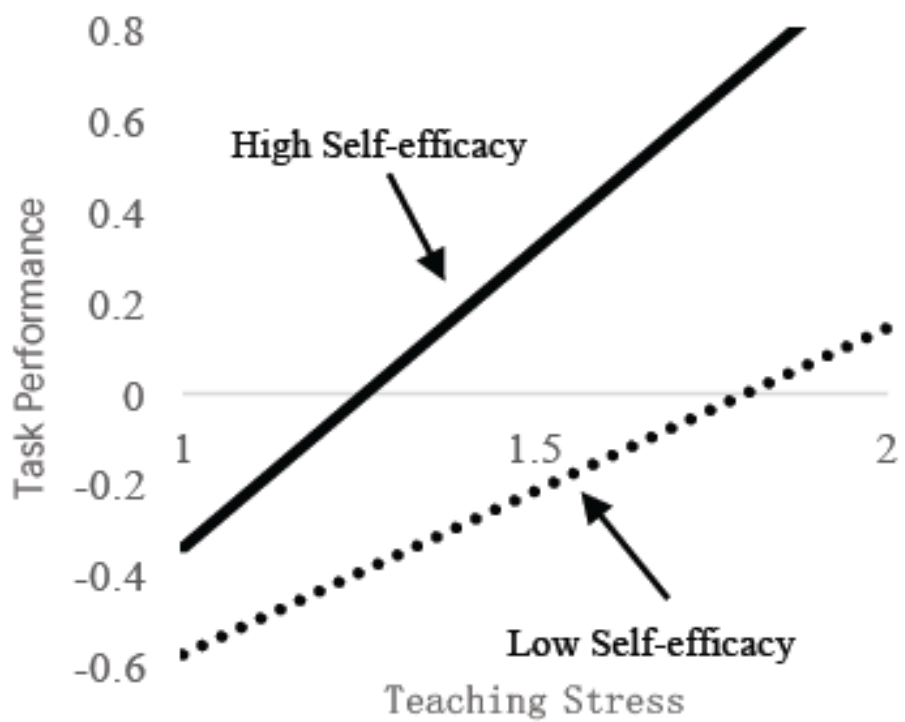

Figure 4 The Third Moderating Effect of Self-efficacy

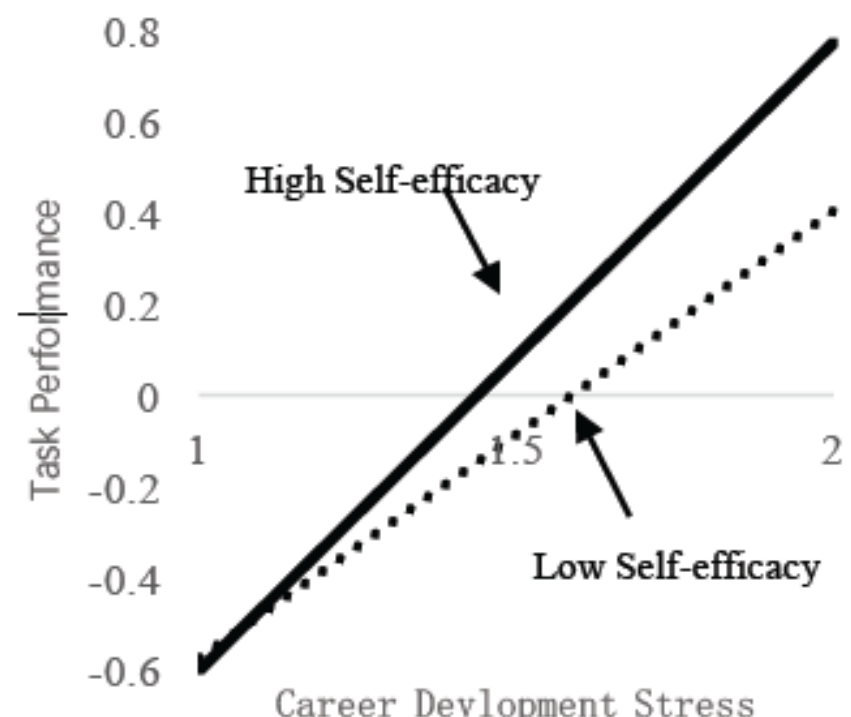

Figure 5 The Fourth Moderating Effect of Self-efficacy 
Table 3 Descriptive Statistics and Correlation Coefficients Matrix $(\mathrm{N}=272)$

\begin{tabular}{|l|l|l|l|l|l|l|l|l|l|}
\hline Variables & 1 & 2 & 3 & 4 & 5 & 6 & 7 & 8 & 9 \\
\hline $\begin{array}{l}\text { Relationship } \\
\text { Stress }\end{array}$ & 1 & & & & & & & & \\
\hline $\begin{array}{l}\text { Research } \\
\text { Stress }\end{array}$ & $.462^{* *}$ & 1 & & & & & & & \\
\hline $\begin{array}{l}\text { Teaching } \\
\text { Stress }\end{array}$ & $.519^{* *}$ & $.511^{* *}$ & 1 & & & & & & \\
\hline $\begin{array}{l}\text { Career } \\
\text { Development } \\
\text { Stress }\end{array}$ & $.450^{* *}$ & $.652^{* *}$ & $.529^{* *}$ & 1 & & & & & \\
\hline $\begin{array}{l}\text { Task } \\
\text { Performance }\end{array}$ & $.446^{* *}$ & $.519^{* *}$ & $.515^{* *}$ & $.455^{* *}$ & 1 & & & & \\
\hline $\begin{array}{l}\text { Relationship } \\
\text { Performance }\end{array}$ & $.531^{* *}$ & $.428^{* *}$ & $.468^{* *}$ & $.366^{* *}$ & $.736^{* *}$ & 1 & & & \\
\hline $\begin{array}{l}\text { Occupational } \\
\text { Stress }\end{array}$ & $.116^{* *}$ & $.089^{* *}$ & $.129^{* *}$ & $.148^{* *}$ & $.035^{* *}$ & $.057^{* *}$ & 1 & & \\
\hline Self-efficacy & $.730^{* *}$ & $.828^{* *}$ & $.782^{* *}$ & $.854^{* *}$ & $.600^{* *}$ & $.547^{* *}$ & $.152^{*}$ & 1 & 1 \\
\hline $\begin{array}{l}\text { Work } \\
\text { Performance }\end{array}$ & $.536^{* *}$ & $.486^{* *}$ & $.513^{* *}$ & $.419^{* *}$ & $.872^{* *}$ & $.973^{* *}$ & $.053^{* *}$ & $.600^{* *}$ & 1 \\
\hline
\end{tabular}

Note: ${ }^{* *} \cdot \mathrm{p}<0.01\left(2\right.$-tailed), ${ }^{*} \cdot \mathrm{p}<0.05$ (2-tailed)

Table 4 Results of Hierarchical Regression Analysis $(\mathrm{N}=272)$

\begin{tabular}{|c|c|c|c|c|c|c|c|c|c|}
\hline & \multirow[b]{2}{*}{ Variables } & \multicolumn{4}{|c|}{ Task Performance $(\beta)$} & \multicolumn{4}{|c|}{ Relationship performance $(\beta)$} \\
\hline & & $\begin{array}{l}\text { Model } \\
1\end{array}$ & $\begin{array}{l}\text { Model } \\
2\end{array}$ & $\begin{array}{l}\text { Mode } \\
3\end{array}$ & $\begin{array}{l}\text { Model } \\
4\end{array}$ & $\begin{array}{l}\text { Model } \\
5\end{array}$ & $\begin{array}{l}\text { Model } \\
6\end{array}$ & $\begin{array}{l}\text { Model } \\
7\end{array}$ & $\begin{array}{l}\text { Model } \\
8\end{array}$ \\
\hline \multirow{3}{*}{$\begin{array}{l}\text { Control } \\
\text { Variables }\end{array}$} & Gender & -.598 & -.317 & -.395 & -.437 & .162 & .545 & .480 & .360 \\
\hline & Age & -.092 & -.014 & -.016 & .034 & .646 & .455 & .454 & .557 \\
\hline & Education & .527 & .015 & -.046 & .042 & .595 & -.226 & -.278 & -.117 \\
\hline \multirow{4}{*}{$\begin{array}{l}\text { Independent } \\
\text { Variables }\end{array}$} & $\begin{array}{l}\text { Relationship } \\
\text { Stress }\end{array}$ & & $.206 * *$ & $.210^{*}$ & $.233^{* *}$ & & $.951 * *$ & $.955^{* *}$ & $\begin{array}{l}1.010 * \\
* *\end{array}$ \\
\hline & $\begin{array}{l}\text { Research } \\
\text { Stress } \\
\end{array}$ & & $\begin{array}{l}.305^{* *} \\
*\end{array}$ & $.302^{*}$ & $\begin{array}{l}.299 * * \\
*\end{array}$ & & $.424 * *$ & $.421 * *$ & $.399 * *$ \\
\hline & $\begin{array}{l}\text { Teaching } \\
\text { Stress }\end{array}$ & & $\begin{array}{l}.313^{* *} \\
*\end{array}$ & $\begin{array}{l}.319 * \\
* *\end{array}$ & $\begin{array}{l}.316^{* *} \\
*\end{array}$ & & $.538 * *$ & $.543 * *$ & $.531^{* *}$ \\
\hline & $\begin{array}{l}\text { Career } \\
\text { Developmen } \\
\text { t Stress }\end{array}$ & & .077 & .085 & .086 & & -.010 & -.004 & .003 \\
\hline $\begin{array}{l}\text { Moderate } \\
\text { Variables }\end{array}$ & Self-efficacy & & & $.060^{*}$ & $\begin{array}{l}.099 \\
*\end{array}$ & & & $.051^{*}$ & $.174^{*}$ \\
\hline \multirow{8}{*}{$\begin{array}{l}\text { Interactive } \\
\text { Items }\end{array}$} & $\begin{array}{l}\text { Relationship } \\
\text { Stress } \times \\
\text { self-efficacy }\end{array}$ & & & & $.074 *$ & & & & $.403 *$ \\
\hline & $\begin{array}{l}\text { Research } \\
\text { Stress } \quad \times \\
\text { Self-efficacy } \\
\end{array}$ & & & & $.168 *$ & & & & $.071^{*}$ \\
\hline & $\begin{array}{l}\text { Research } \\
\text { Stress } \quad \times \\
\text { Self-efficacy }\end{array}$ & & & & $.558 *$ & & & & $1.312^{*}$ \\
\hline & $\begin{array}{l}\text { Career } \\
\text { Developmen } \\
\text { t Stress } \times \\
\text { Self-efficacy }\end{array}$ & & & & $.588 *$ & & & & $1.797 *$ \\
\hline & $\mathrm{R}^{2}$ & .009 & .385 & .389 & .409 & .005 & .355 & .356 & .386 \\
\hline & $\Delta \mathrm{R}^{2}$ & .009 & .376 & .004 & .020 & .005 & .350 & .001 & .030 \\
\hline & F & .408 & $\begin{array}{l}16.335 \\
* * *\end{array}$ & $\begin{array}{l}15.04 \\
9 * * *\end{array}$ & $\begin{array}{l}11.822 \\
* * *\end{array}$ & .205 & $\begin{array}{l}14.368 \\
* * *\end{array}$ & $\begin{array}{l}13.049 \\
* * *\end{array}$ & $\begin{array}{l}10.733 \\
* * *\end{array}$ \\
\hline & $\Delta \mathrm{F}$ & .408 & $\begin{array}{l}39.867 \\
* * *\end{array}$ & $\begin{array}{l}1.734 \\
* * *\end{array}$ & $\begin{array}{l}2.190 * \\
* *\end{array}$ & .205 & $\begin{array}{l}35.454 \\
* * *\end{array}$ & $.264 * *$ & $\begin{array}{l}3.167 * \\
* *\end{array}$ \\
\hline
\end{tabular}

Note: ${ }^{* * *} \cdot \mathrm{p}<0.001$ (2-tailed); ${ }^{* *} \cdot \mathrm{p}<0.01$ (2-tailed); ${ }^{*} \cdot \mathrm{p}<0.05$ (2-tailed) 


\section{Discussion}

\section{General Discussion}

In our research, 272 young college teachers were selected as research samples, and the data were collected by questionnaire survey. We used SPSS20.0 as statistical analysis tools to analyze the relationships among occupational stress, self-efficacy and occupational performance.

The results indicate that occupational stress can exert a positive impact on occupational performance. The relationship stress, research stress, teaching stress and career development stress of university young teachers can promote their task performance and relationship performance. That is, with the increasing pressure, the performance of university young teachers will increase. However, Miller (1960) once suggested that in a system, stressors could cause overloading of information, due to the neglect of relevant information or the loss of information and the control of inaccurate information, employees mightignore some of the potential information which may lead to a higher probability of making mistakes at work [21]. Huang Haiyan (2014) further concluded that there is an inverted U-shaped relationship between job stress and job performance [22]. In other words, the positive correlation between work pressure and work performance is established within a certain range. When the pressure breaks through a critical value, it will inevitably lead to the decline of work performance.

To further determine the relationship between university young teachers' work pressure and job performance, we conducted in-depth interviews with some young university teachers and university administrators. Those interviewed young teachers considered that the current work pressure is sustainable but if the pressure is greater, they might not withstand it. For example, the interviewed young teachers said that their university regulations require each teacher to undertake a certain amount of teaching tasks within a period of three years, he/she must successfully apply for a certain level of scientific research and publish two papers in core journals. And this research pressure is affordable for the vast majority of young teachers.But in terms of job evaluation, papers needed to be published and the amount of scientific research task are 5 to 6 times more than the standard of continuing to be employed.It is difficult for some university young teachers to complete it. Therefore, the empirical conclusions drawn in our study are only the result of data analysis. According to the contents of the in-depth interviews, the positive and negative correlations are only within the acceptable range, but the specifics of affordability need to be further explored.

Self-efficacy moderates the relationship between university young teachers' occupational stress and occupational performance, suchthatthe relationship is stronger for university young teachers with high levels of self-efficacy than for those with low levels of self-efficacy.In general, when confronting the same stress, university young teachers who have higher self-efficacy will have more confidence and they will show a higher sense of responsibility, which will lead to more efforts to achieve the goal of work performance.

\section{Theoreticaland Practical Implications}

It is common for university young teachers to reduce work performance due to excessive work pressure. It is essential to improve the performance of university young teachers through improving self-efficacy, and it is a key issue that university administrators should pay attention to. The conclusion of our study is of great significance for the management of university young teachers working pressure, self-efficacy and job performance. In practice, universities should take the initiative to understand the job demands, personality differences and psychological conditions of young university teachers and adopt different measures to improve the performance of university young teachers.

Specifically, in terms of interpersonal relationships, administrators should take the adaptability of university young teachers from students to university teachers into account in the formulation of rules and regulations and they are supposed to strive to achieve a balanced relationship among young teachers and leaders, co-workers and students. For scientific research, because the quality of scientific research not only depends on their own abilities but also inseparable from the school's support and help. Therefore, papers that need to be published for young teachers should be adjusted 
according to the differences of young teachers. In terms of teaching and career development, administrators need to help young teachers to improve self-efficacy, such as giving more positive feedback to them and so forth. In addition, administrators can make some efforts to solve the pressure of university young teachers 'life so as to help them focus on teaching and scientific research.

\section{LimitationsandFuture Research}

Although we tried to be rigorous in the research methods, subjects of the research, the collection and distribution of questionnaires, statistical analysis of the data, essay writing and revising and so on, there are some limitations in our research due to the research scope and time. In this study, we only introduced self-efficacy as a moderate variable. The following research can add variables such as social support, and use MPLUS and other data analysis software to further verify its regulatory role.

\section{References}

[1]Bandura A. Self-efficacy: toward a unifying theory of behavioral change. Psychological Review, 1977, 84(2): 191.

[2] Yong-Zhou Li, Yue Wang, Jing-Ning Yang. Research on the impact of self-efficacy and job input on the work performance of high-tech enterprise $\mathrm{R} \& \mathrm{D}$ staff.Science and Management in Science and Technology, 2015 (2): 173-180.

[3]Yerkes, R. and Dodson, J. The relation of strength of stimulus to rapidity of habit-formation, Journal of Comparative and Neurological Psychology, 1908(18):459-482.

[4]Jamal, M. Job stress and job performance controversy: An empirical assessment Organizational Behavior and Human Performance, 1984 (33): 1-21.

[5]Scott, W. E. Activation theory and task design. Organizational Behavior and Human Performance, 1966(1):3-20.

[6]Jacobs P A, Tytherleigh M Y, Webb C, et al. Predictors of work performance among higher education employees: An examination using the ASSET model of stress. International Journal of Stress Management, 2007, 14(2):199-210.

[7] Tian-Yin Liu.Study on the work pressure of university teachers based on system simulation. Huazhong University of Science and Technology, 2010.

[8] Jian-Wei Li.The relationship between job stress and job performance of college teachers. Yanshan University, 2012.

[9] Yang-Chun Fang.Effect of work pressure and social support on college teachers' performance.Science\& Management. 2013, 6 (5): 136-143.

[10]Bandura A. Editorial. American Journal of Health Promotion, 1997, 12(1): 8-10.

[11] Yuan-Dong Gu, Ji-Sheng Peng.Research on the impact mechanism of innovation self-efficacy on employees' innovative behavior.Science and Management, 2011, 32 (9): 63-73.

[12] Ding-Kun Zhang, Li-Luo Fang, Wen-Quan Ling. The theory and research status of self-efficacy.Advances in Psychological Science, 1999, 16 (xl): 39-43.

[13] Chang-Qin Lu, Wen- Quan Ling, Li-Luo Fang. Effects of managerial self-efficacy on managerswork-related attitudes and performances: An exploratory study in China.ActaScientiarumNaturaliumUniversitatisPekinensis, 2006, 42 (2): 276-280.

[14] Dong-Dong Feng, Chang-Qin Lu, Ai-Ling Shao.JobInsecurity, well-being,and jobperformance:Theroleof general self-efficacy. ActaPsychologicaSinica, 2008,40 (4): 448-455 
[15] Xiao-Bin Meng, Xiao-dong Xu. The performance attributes of business manager's working stress:An explanation based on self- efficacy. journal of Business Economics, 2008, 1 (11): 27-33.

[16]Li-Xian Yang.Chinese Marxist youth outlook [D].CPC Central Party School, 2013.

[17] Li-junGuo, Qing-Ming Zhou. The development of junior faculty in local institutions of higher education. Journal of Higher Education, 2011 (18): 65-69.

[18] Zhao-Hua Jiang, Zhong-Ping Yao, Zhi-Liang Wang, etc. Relying on curriculum construction to train young teachers' teaching ability. China University Teaching, 2013 (1): 82-84.

[19]Archibong, IjeomaAniedi, Bassey, AkpoOffiong, Effiom, David Out. Occupational stress sources among university academic staff. European Journal of Educational Studies, 2010(3):217-225.

[20]Riggs M L, Warka J, Babasa B, et al. Development and validation of self-efficacy and outcome expectancy scales for job-related applications. Educational and Psychological Measurement, 1994, 54(3):793-802.

[21]Miller J G. Information input overload and psychopathology. American Journal of Psychiatry, 1960, 116(8):695-704.

[22] Hai-Yan Huang. The impact of job stress on R\&D workers' job performance: Moderating role of performance appraisal orientation. Science of Science and Management of S. \& T., 2014 (7): 162-170. 